\title{
O USO DO “NOME SOCIAL” EM UMA UNIVERSIDADE PÚBLICA BRASILEIRA: QUESTÕES DE IDENTIDADE DE GÊNERO
}

\section{THE USE OF THE "SOCIAL NAME" IN A BRAZILIAN PUBLIC UNIVERSITY: GENDER IDENTITY ISSUES}

\author{
Gabriel Marchetto ${ }^{1}$, Jaqueline Ângelo dos Santos Denardin² \\ 1 Secretaria de Estado de Educação de Mato Grosso, Brasil, E-mail: \\ gabriel.marchetto@professor.mt.gov.br, ORCID: https://orcid.org/0000-0003-2535-1723 \\ 2 Universidade Federal de Mato Grosso, Brasil, E-mail: jaquelinedenardin@hotmail.com, ORCID: \\ https://orcid.org/0000-0002-2982-6573
}

ARTICLE INFO

Article history:

Received 2020-06-01

Accepted 2020-11-30

Available online $2020-11-30$
Palavras-chave: Gênero. Análise do discurso. Nome social. Universidade.

Keywords: Gender. Discourse analysis. Social name. University.

RESUMO. Este trabalho, sob a perspectiva teórica da Análise de Discurso (PÊCHEUX, 1975), tem como objetivo analisar uma normativa de uma universidade pública estadual que trata sobre o uso do nome social na universidade. Interessa-nos responder neste trabalho os seguintes questionamentos: como compreender a formulação "Nome Social"? Como a instrução normativa da universidade mobiliza ou não discussões sobre identidades de gênero, sexualidades para definir "Nome Social"? Como a instrução produz sentidos e afeta a vida acadêmica? Desse modo, pretende-se compreender a relação entre o processo de constituição dos sujeitos e as práticas discursivas que organizam sentidos sobre a identificação de gênero a partir de uma instrução que autoriza a utilização do "Nome Social".

\begin{abstract}
This work, under the theoretical perspective of Discourse Analysis (PÊCHEUX, [1975]), aims to analyze Joint Service Instruction n. 001/2016-PROGRAD / PRPPG-UNIOESTE, which deals with the use of the social name in the university. We are interested in answering in this work the following questions: how to understand the formulation "Social Name"? How does UNIOESTE's education mobilize discussions about gender identities, sexualities to define "Social Name"? How does education produce meaning and affect academic life? In this way, we intend to understand the relation between the process of constitution of the subjects and the discursive practices that organize senses about the identification of gender from an instruction that authorizes the use of the "Social Name".
\end{abstract}

\section{Introdução}

Desde o momento em que o sujeito nasce, o nome a que este é imposto irá acompanhá-lo e distingui-lo na sociedade perante os demais, iniciando essa identificação pela esfera familiar que se estenderá pelas demais esferas da sociedade, inclusive e, de modo muito incisivo, na esfera educacional/universitária. Nome este que impõe uma imagem sobre o sujeito - uma imagem relacionada ao sexo biológico, correlacionado com aspectos convencionais sociais - do masculino e do feminino, atribuindo a este(s) sujeito(s) 
características que foram construídas e convencionadas socialmente, logo inserindo o sujeito em uma formação ideológica que se tem a respeito de determinado gênero ao qual pertence - ou acredita-se que deve pertencer, em função desse nome que lhe é conferido no nascimento e que vem carregado de sentidos e motivos para o ser - relação entre o nome e o sujeito que o usufrui, a qual vem ser contraditória/equívoca quando se trata do sujeito transexual/travesti ${ }^{1}$, sujeito este que geralmente faz/tenta fazer o uso do Nome Social (NS). Nome social é o nome pelo qual pessoas trans/travestis preferem ser chamadas cotidianamente, em contraste com o nome oficialmente registrado que não reflete sua identidade de gênero.

Atualmente este tema, o uso do NS, tem repercutido em várias esferas e instituições sociais, como é o caso do uso do nome social em universidades, a exemplo disso, temos a UNIOESTE (Universidade Estadual do Oeste do Paraná), que, em 2016, legalizou o uso do Nome Social, a partir de uma Instrução de Serviço Conjunta, que possibilita ao sujeito que pode/deve/quer fazer o uso do nome social, em seus sistemas internos. Valendo-se dessa Instrução de Serviço Conjunta, o sujeito deve protocolar junto à Secretaria Acadêmica um pedido de "uso do Nome Social", que será reconhecido após avaliação interna sobre o pedido protocolado, que, depois será deferido - ou não - legalizando o uso do Nome de "tratamento" do sujeito nas dependências da Universidade.

O Discurso Jurídico (DJ)2 é visto como uma forma de regulamentação do social, ou do controle social, que visa adaptar a conduta das pessoas, a padrões e comportamentos dominantes. Considerando que a sociedade não é estática, ou seja, está em constante mudança, faz-se necessária a mudança/adaptação das leis para que estas possam garantir a ordem, uma vez que uma das finalidades funcionais do Direito é prevenir e compor conflitos, entre as quais a função preventiva é mais importante.

Para corroborar com os estudos sobre o tema abordado, trago a citação de Maria Berenice Dias (2014),

Direito à identidade de Gênero: a livre expressão da identidade de gênero é reconhecida a transexuais, travestis e intersexuais, que têm direito ao uso do nome social, independente da realização da cirurgia de resignação sexual ou da alteração do nome registral. $O$ direito à retificação do nome e da identidade sexual no Registro Civil independe da cirurgia de transgenitalização. Para a adequação do sexo morfológico à identidade de gênero é garantida realização dos procedimentos de hormonioterapia e transgenitalização pelo SUS (Sistema Único de Saúde). Havendo indicação terapêutica da equipe médica e multidisciplinar, procedimentos complementares não cirúrgicos de adequação de gênero podem iniciar a partir dos 14 anos de idade, mas a cirurgia de resignação sexual somente pode ser realizada a partir dos 18 anos. É vedada a realização de qualquer intervenção médico-cirúrgica de caráter irreversível para a determinação de

\footnotetext{
${ }^{1}$ Entende-se neste artigo que o/a transexual e o/a travesti são nomeações para o mesmo sujeito, a diferença entre os termos se dá em relação ao prestígio social do primeiro sobre o segundo, portanto, ambos serão referenciados como o sujeito Trans.

${ }^{2}$ Discurso Jurídico, neste artigo, é entendido como todo e qualquer texto que possua normas, leis e/ou outros instrumentos jurídico-legais, que sirvam como base legal e institucional para a aplicabilidade na sociedade.
} 
gênero em recém-nascidos e crianças diagnosticadas como intersexuais. Em todos os espaços públicos e abertos ao público é assegurado o uso das dependências e instalações correspondentes à identidade social. O uso do nome social é garantido nos estabelecimentos de ensino, devendo constar em todos os registros acadêmicos. Igual garantia é assegurada nas relações de trabalho, devendo o nome social ser inserido na Carteira de Trabalho e nos assentamentos funcionais. (DIAS, 2014, p.268)

As discursividades que permeiam o sujeito Trans carregam consigo formações ideológicas e imaginárias, muitas vezes, que violentam e depreciam esse sujeito. Tendo em vista que ele pertence à população LGBT $^{3}$, (Lésbicas, Gays, Bissexuais e Travestis/Transexuais) é diversas vezes marginalizado, seja pela sociedade ou pela mídia, uma vez que esta interpela os indivíduos em função de reforçar os discursos de marginalização e intolerância sobre o sujeito Trans.

Diante dessas considerações, este texto busca, em um primeiro momento, apresentar nossa perspectiva teórica (Análise de Discurso de base pecheutiana) e, em seguida, analisar como a instrução elencada diz sobre os sujeitos Trans e seu/do Nome Social.

\section{Um pouco de teoria: Algumas considerações sobre Análise de Discurso}

A análise do discurso surge da relação entre três áreas: o materialismo histórico, como a teoria das formações e suas transformações, entendido como a teoria das ideologias, a linguística, como a teoria dos mecanismos sintáticos e dos processos de enunciação ao mesmo tempo, e a teoria do discurso, como a teoria da determinação histórica dos processos semânticos. É importante destacar que essas três áreas citadas são interpeladas por uma teoria da subjetividade, considerada de natureza psicanalítica.

A passagem de um discurso a outro é acompanhada de uma mudança na estrutura e no funcionamento dos grupos que gerem esses discursos. As instituições é que tornam o discurso possível, a relação do homem com a natureza é antes de tudo a relação social, essas instituições parecem submetidas ao mesmo processo de estruturação do discurso propriamente dito. A intertextualidade desenha implicitamente as regras de um modo de existência. A passagem de um discurso a outro é acompanhada de uma mudança na estrutura e no funcionamento dos grupos que gerem esses discursos.

Existe uma imbricação entre discurso e instituição, que se constituem um ao outro, em uma estrutura complexa. O discurso ocorre no interior de uma determinada instituição, que dita, por exemplo, o que se pode dizer, quem pode dizer e o valor do que diz. Se ocorre uma mudança de dominação discursiva, isto é, uma mudança de instituição, esta mudança se dá em termos de semântica global, não é realizada de forma gradual, mas ocorre na forma de substituição de um conjunto de enunciadores por outros. Os enunciadores, por sua vez,

${ }^{3}$ LGBT é o acrônimo de Lésbicas, Gays, Bissexuais, Travestis, Transexuais e Transgêneros. Em uso desde os anos 1990, o termo é uma adaptação de LGB, que era utilizado para substituir o termo gay para se referir à comunidade LGBT no fim da década de 1980. 
definem seu estatuto e seu modo de enunciação inscrevendo-se em uma certa posição social.

Neste trabalho, para compreendermos o documento analisado, foram mobilizados os conceitos de Formação discursiva, Formação Ideológica, Formação Imaginária, levando em conta também as Condições de Produção, o conceito de transexualidade e nome Social, considerando o Lugar que estes sujeitos ocupam discursivamente e as ideologias que marginalizam esses sujeitos.

Segundo Orlandi (2013), a noção de formação discursiva permite compreender o processo de produção dos sentidos, a sua relação com a ideologia, possibilitando estabelecer regularidades no funcionamento do discurso. No entanto, este sentido não é tal qual aquele que acreditamos ter construído em nossa mente, ele é na verdade um efeito de sentido, que se completa no interlocutor.

São as formações discursivas que determinam o que pode ou não ser dito. Para que possamos dizer algo, para que se possa enunciar, é preciso estar inserido em uma formação discursiva. Diferentes culturas, diferentes formações discursivas fazem com que atribuamos efeitos de sentido diferentes, interpretando-os de acordo com a ideologia na qual estamos mergulhados. Esse posicionamento é diferente para cada um e está relacionado à história, à classe social, aos valores morais, religiosos e à nossa relação entre cultura e língua. A linguagem é subjetiva, ou seja, presume a existência de um sujeito.

O sentido é assim uma relação determinada do sujeito - afetado pela língua - com a história. É o gesto de interpelação que realiza essa relação do sujeito com a língua, com a história, com os sentidos. Esta é a marca da subjetivação e, ao mesmo tempo, o traço da relação da língua com a exterioridade: não há discurso sem sujeito. E não há sujeito sem ideologia. Ideologia e inconsciente estão materialmente ligados. (ORLANDI, 2013, p.47)

Toda a relação que temos com o mundo que nos cerca é através da linguagem, que é passível de equívocos, moldada por ideologias e vozes que nos precedem. Entende-se, então, que o sujeito para a Análise do Discurso é o sujeito do inconsciente, que jamais termina de se constituir. Ele não é coerente com todas as posições que vem a assumir, não está terminado, portanto, pode ter posicionamentos diversos sobre o mesmo assunto, em momentos distintos.

Nenhum dizer acontece sempre da mesma maneira e o sentido também nunca é garantido, no entanto, as condições de produção são sempre únicas. Essas condições históricas de produção nos remetem às relações de força presentes e constituintes da prática discursiva. Para Orlandi (2013), as condições de produção compreendem fundamentalmente os sujeitos e a situação, e a maneira como a memória as aciona. Para Pêcheux, 
Dito de outro modo, a espécie discursiva pertence, assim pensamos, ao gênero ideológico, o que é o mesmo que dizer que as formações ideológicas de que acabamos de falar "comportam necessariamente, como um de seus componentes, uma ou várias formações discursivas interligadas que determinam o que pode $\mathrm{e}$ deve ser dito a partir de uma posição dada numa conjuntura. (PÊCHEUX 1997, p. 166)

Logo, o sujeito fala a partir do lugar que ocupa, ou seja, quando o sujeito muda de lugar, sua formação discursiva será outra, pois as condições de produção serão outras. Assim sendo, o discurso está sempre em movimento e assumindo/produzindo vários sentidos que são (re)significados a todo instante pelos sujeitos, os quais são assujeitados pelas ideologias existentes nesses discursos, que são formados por uma memória discursiva.

Pêcheux, diz sobre Memória que é aquilo que já foi dito, esquecido, mas que significa, é a memória que faz emergir os sentidos em nós. Quando falamos em memória, este conceito não está vinculado à memória de uma pessoa, mas sim a um "saber discursivo", que está na base de todos os dizeres, que possibilita que o que é dito pelo sujeito faça sentido. A memória não se ativa, em AD a memória é retomada. A memória na perspectiva do interdiscurso é aquilo que foi dito antes, em outro lugar, independentemente. Assim, PÊCHEUX (2009) afirma:

Por outro lado, apelamos para a noção de "sistema inconsciente" para caracterizar um outro "esquecimento", o esquecimento $n^{\circ} 1$, que dá conta do fato de que o sujeito-falante não pode, por definição, se encontrar no exterior da formação discursiva que o domina. Nesse sentido, o esquecimento no1 remetia, por uma analogia com o recalque inconsciente, a esse exterior, na medida em que - como vimos - esse exterior determina a formação discursiva em questão. (PÊCHEUX, 2009, p.162)

$\mathrm{Na} A D$, o sujeito é o sujeito do inconsciente, portanto, este não é dono do seu dizer, como afirma PÊCHEUX (2015), "o processo do discurso não deve, evidentemente, ser confundido com o ato de fala do sujeito falante individual, noção que se torna inútil e perigosa à medida que o estudo dos processos (não centrados sobre um "sujeito falante") faz aparecer o caráter empírico e respectivo desta noção".

\section{Análise de uma instrução: como se diz sobre o sujeito trans?}

O corpus de análise para este artigo é uma Instrução de Serviço Conjunta de uma universidade pública estadual brasileira, a qual resolve instruir conjuntamente a inclusão e utilização do nome social nos registros acadêmicos internos da instituição.

Portanto, para compreendermos a atuação dessa instrução na universidade, é relevante saber sobre a significância/importância de uma instrução na esfera jurídica, e, de acordo com a pirâmide de Kelsen, as instruções estão na base da pirâmide, sendo assim, submetidas à hierarquia de poder de qualquer outro instrumento jurídico que venha a 
(co)existir e compartilhar do mesmo "objeto" de uma determinada instrução, sendo sujeita a todos os demais instrumentos jurídicos.

A instrução em si é carregada de efeitos de sentidos em relação ao(s) sujeito(s) que ela aborda, seja este sujeito o do nome social ou aquele da identidade de gênero, distinção inscrita na própria instrução,

Considerando que o não reconhecimento da identidade de gênero e do nome social se caracteriza como violência simbólica e adoção do uso do nome social garante o respeito a identidade de gênero de pessoas trans no âmbito da UNIOESTE evitando constrangimentos, estigmas, preconceitos, violência e a evasão escolar dessas pessoas [...] (INSTRUÇÃO DE SERVIÇO CONJUNTA N.001/2016-PROGRAD/PRPPG-UNIOESTE)

Tal objeto, no caso a instrução, traz o entendimento/esclarecimento sobre as pessoas que podem fazer o uso dessa, sendo aquelas que se auto identificam e são reconhecidas no meio social com um nome diferente do seu de registro, Nome Civil (NC) ${ }^{4}$, e aquelas que se identificam com um gênero sexual, oposto ao seu de nascimento, sendo considerada essa experiência como interna e individual de cada indivíduo, que pode ou não corresponder ao sexo "atribuído" no nascimento, tal instrução ainda trata do senso pessoal do corpo, que pode envolver por livre escolha modificação da aparência ou função corporal. Dessa forma, os sentidos vão sendo produzidos para os diferentes sujeitos e, segundo Eni Orlandi,

a Análise de Discurso visa à compreensão de como um objeto simbólico produz sentidos, como ele está investido de significância para e por sujeitos. Essa compreensão, por sua vez, implica em explicitar como o texto organiza os gestos de interpretação que relacionam sujeito e sentido. Produzem-se assim novas práticas de leitura. (ORLANDI, 2013, p. 26).

A instrução ainda traz em seu texto a explicação de que o termo "Nome Social" constará em formulários e sistemas de informação, nos quais o nome social será incluído, precedido do termo Nome Social, ou prefixo NS, antes do nome escolhido pelo "discente", colocando a exemplo, "NOME SOCIAL: Fulano de Tal", que, segundo a instrução, justifica-se a fim de possibilitar a "visualização imediata do nome" e permitir que a secretaria acadêmica altere o registro antes da emissão dos documentos.

Essa instrução foi pensada com o intuito de combate à violência simbólica sofrida por pessoas que podem/devem/querem fazer o uso do seu nome social e, por assim ser, foi considerada a resolução n. 12/15 do Conselho Nacional de Combate à Discriminação e Promoção dos direitos de Lésbicas, Gays, Travestis e Transexuais, vinculada à Secretaria de Direitos Humanos, que estabelece parâmetros para a garantia das condições de acesso e permanência de pessoas travestis e transexuais - e todas aquelas que tenham sua identi-

\footnotetext{
${ }^{4}$ Entenda-se por Nome Civil aquele que está no Registro Geral (RG), que serve para cadastro de pessoas no SSP -Serviço de Segurança Pública, popularmente, conhecido como nome de registro.
} 
dade de gênero não reconhecida em diferentes espaços sociais nos sistemas e instituições de ensino, formulando orientações quanto ao reconhecimento institucional da identidade de gênero e sua operacionalização.

Existem políticas e leis que organizam a sociedade e servem/deveriam servir para manter a ordem e para garantir que tudo aquilo que está institucionalizado é válido. Assim, os discursos que atravessam os instrumentos normativos são escritos por sujeitos com Formação(es) Ideológica(s) diferente(s), possibilitando um deslize na produção/interpretação de sentidos para um determinado sujeito. Como afirma Orlandi,

Consequentemente, podemos dizer que o sentido não existe em si mas é determinado pelas posições ideológicas colocadas em jogo no processo sócio-histórico em que as palavras são produzidas. As palavras mudam de sentido segundo as posições que as empregam. Elas "tiram" seu sentido dessas posições, isto é, em relação as formações ideológicas nas quais essas se inscrevem (ORLANDI, 2013, p. 42-43).

Portanto, os efeitos de sentidos produzidos a partir de um determinado discurso já vêm carregados de dizeres atravessados por ideologia(s) exteriores ao sujeito desse discurso. Para Orlandi,

as palavras não têm um sentido nelas mesmas, elas derivam seus sentidos das formações discursivas em que se inscrevem. As formações discursivas por sua vez, representam nos discursos as formações ideológicas. Desse modo, os sentidos sempre são determinados ideologicamente (ORLANDI, 2013, p.43)

A instrução da universidade acerca do uso do Nome Social foi pensada com o intuito de diminuir as diferentes formas de violência em relação ao indivíduo que faz uso do nome social, porém esse mesmo sujeito, ao fazer o uso deste, que é lhe conferido como direito, é marcado por formações histórico-ideológicas, nas quais o Nome Social possui uma "carga negativa", trazendo consigo toda a formação imaginária sobre o sujeito do Nome Social, pois o indivíduo que faz seu uso, não é tido como verdadeiro, uma vez que existe o seu nome de registro ou Nome Civil, logo o Nome Social não tem a mesma "importância" do Nome civil. Dessa forma nós temos um sujeito, como diz Orlandi,

atravessado pela linguagem e pela história, sobre o modo do imaginário, o sujeito só tem acesso a parte do que diz. Ele é materialmente dividido desde sua constituição: ele é sujeito de e é sujeito à. Ele é sujeito à língua e à história, pois para se constituir, para (se) produzir sentidos ele é afetado por elas. Ele é assim determinado, pois se não sofrer efeitos do simbólico, ou seja, se ele não se submeter à língua e à história ele não se constitui, ele não fala, não produz sentidos (ORLANDI, 2013, p.48-49).

O sujeito que faz o uso do Nome Social está circundado pelos sentidos que foram produzidos no decorrer da história sobre o Nome Social. Os sujeitos que utilizam do Nome Social são os sujeitos Trans, logo, as formações ideológicas e imaginárias acerca do sujeito que se identifica e se (re)afirma como transexual ou travesti sustentarão os sentidos sobre 
esses sujeitos, sentidos estes que historicamente filiam-se a imagem que violenta e deprecia esses sujeitos. Essa violência reforçada nos discursos que se referem aos sujeitos Trans.

\section{Conclusão}

A princípio a instrução traz recortes de vários outros instrumentos normativos, como se estivesse se auto justificando, e, dessa forma, aparece apenas como se concedendo um direito que já está previsto em lei, o qual esta instituição acatou devido às intervenções de alguns sujeitos.

Reforçando a ideia de que a instrução existe apenas para que seja concedido o direito de utilização do nome social, a instituição não garante e nem promove a discussão e o conhecimento sobre este instrumento legal, isso se torna evidente pelo desconhecimento de funcionários da existência de um instrumento legal, que normatiza a utilização do nome social, e quando reconhecido este instrumento, não se tem domínio/conhecimento da sua aplicabilidade.

É perceptível que não há um "entendimento/conhecimento" público - e tudo nos leva a crer, que não há interesse que aconteça esse reconhecimento acerca do sujeito Trans - do que seja o transexual, e isso já foi percebido também por Bento (2012, p. 19), que assim ressalta: "as definições do que seja um/a homem/mulher de 'verdade' se refletem e emergem nas definições do que seja um/a transexual de 'verdade'”. Esta afirmação de Bento é reforçada pela formação imaginária engendrada nos sujeitos sobre o sujeito Trans, uma vez que os próprios funcionários do estabelecimento não reconhecem como Trans, e que faz o uso do Nome Social, aquele sujeito que é feminino e não possui traços masculinos, de acordo com funcionários do estabelecimento, baseado em sua formação imaginária, só pode ser Trans se o sujeito tiver traços, convencionados socialmente, masculinos ${ }^{5}$

Discursos estes que estão reforçando a ideia de que os sujeitos Trans não sabem quem são de verdade, ou que estes são uma inverdade, algo falso, mentiroso, que não existe, ou não deveria existir, e se pensarmos nessa sequência de ideias, é nessa forma de dominação ideológica que os discursos de ódio e intolerância se fundamentam e se materializam.

Os conceitos formulados, legalizados ou não, para as pessoas Trans têm como base a heteronormatividade, como Bento traz na citação de Butler:

${ }^{5}$ Observações feitas a partir de conversas informais com funcionários da instituição, com o intuito de averiguar questões de reconhecimento dos sujeitos trans. 
Transexualidade, travestibilidade, transgênero são expressões identitárias que revelam divergências com as normas de gênero uma vez que estas são fundadas no dimorfismo, na heterossexualidade e nas idealizações. As normas de gênero definirão o considerado "real", delimitando o campo no qual se pode conferir humanidade aos corpos. (BUTLER,1990., apud BENTO, 2012, p.20)

Novamente é reforçado o fato de que as "normas" para os sujeitos Trans são aquelas criadas pelos sujeitos héteros, e que estes se utilizam das facetas "negativas" para mobilizar as normas para os sujeitos Trans, utilizando-se de conceitos negativos e pejorativos, a exemplo dimorfismo.

Outro exemplo disso é quando observamos a inclusão da transexualidade no rol dos "Transtornos de Identidade de Gênero", no capítulo dedicado aos "Distúrbios de Identidade de Gênero", no Manual de Diagnósticos e Estatísticas de Distúrbios Mentais (DSM). Ou seja, vivemos em uma sociedade, na qual a transexualidade é tratada/vista como doença, doença esta que deve ser erradicada a qualquer custo, inclusive com a morte, isto verifica-se em noticiários em que o Brasil aparece como o país que mais mata sujeitos Trans no mundo.

O Brasil é um país com conceitos muito engessados em relação às questões de gênero e, quando se trata de legislar, mesmo que seja para a população Trans, estes ainda se baseiam em conceitos heteronormativos, que se limitam ao tratamento de mulher apenas como a mulher cis gênero e o homem cis gênero, não reconhecendo e validando os sujeitos "diferentes" destas concepções de gênero e suas diversidades. Essas autoridades ficam apenas na discussão binária de gênero, que compreende o feminino e o masculino, desprezando os demais e, por assim serem, é como se os sujeitos Trans não existissem.

Em contrapartida, a instrução analisada que trata do uso do nome social, coloca - e expõe - o sujeito que faz o uso desse direito que the é conferido por lei, o que se verifica com o prefixo "NS", na frente do nome do sujeito - que faz o uso do nome social colocando este em situação de constrangimento e, algumas vezes, em situação vexatória, pensando no desconhecimento em relação a este instrumento normativo, que é - ou deveria ser - um meio para amenizar esse tipo de situação para o sujeito que é afetado (no sentido literal da palavra) por esta instrução.

\section{Referências}

BENTO, B. O que é transexualidade. 2.ed. São Paulo, SP: Brasiliense, 2012.

DIAS, M. B. Diversidade Sexual e Direito Homoafetivo. 2.ed. São Paulo - SP. Editora revista dos tribunais, 2014.

GADET, F.; HAK, T. Por uma análise automática do discurso. Uma Introdução à Obra de Michel Pêcheux. Editora da Unicamp, 1997. 
ORLANDI, E. P. Análise de Discurso Princípios \& Procedimentos. 11.ed. Campinas, SP: Pontes, 2013.

PÊCHEUX, M. Análise de Discurso: Michel Pêcheux. Textos selecionados: Eni Puccinelli Orlandi. 4. ed. Campinas, SP. Editora Pontes, 2015.

Semântica e Discurso: uma crítica à afirmação do óbvio. $4^{a}$ Ed. Campinas SP. Editora da Unicamp. 2009.

UNESP. Portal da Universidade Estadual Paulista. Sobre tratamento nominal de pessoas transexuais e travestis. São Paulo, SP 2015. Disponível em: https://www.unesp.br/portal\#!/aci_ses/notas-e-comunicados/spbre-tratamento-nominal-depessoas-transexuais-e-travestis. Acesso em: 20 de março de 2020. 